\title{
Measuring paternal involvement in childcare and housework
}

\author{
Abstract \\ There is currently no quantitative tool for measuring paternal involvement in childcare and \\ housework. To address this, we run Confirmatory Factor Analysis (CFA) on a sample of households \\ from the 2001-02 sweep of the UK's Millennium Cohort Study. Two quantitative measures of \\ paternal involvement in childcare and housework are derived for when the child is aged nine \\ months old, which appear to be isomorphic with two dimensions of Michael Lamb's paternal \\ involvement: engagement and responsibility. Two, moderately correlated latent variables are \\ produced, which are then used to explore employment and socio-demographic characteristics of \\ involved fathers. Our results show that paternal engagement and responsibility are correlated, \\ albeit weakly, with fathers' employment hours, education and gender role attitudes. The \\ strongest correlation is with mothers' employment hours, which suggests that mothers' \\ employment schedules are more important than fathers' for fostering paternal involvement when \\ the child is aged nine months old. There are also variations in paternal engagement and \\ responsibility according to ethnicity, which suggests cultural differences might interact with the \\ ability of fathers to be involved. This highlights the need for further exploratory analyses on \\ variations of paternal involvement by different ethnic classifications, which has been fairly limited \\ to date.
}

Keywords: Fathers, fatherhood, involvement, childcare, engagement, responsibility, housework, employment hours, ethnicity, Confirmatory Factor Analysis

\section{Introduction}

How to measure paternal involvement is a matter of wide debate (e.g. Dermott 2008, 2003; Williams 2008; Mikelson 2008; Sanderson and Sanders-Thompson 2002; Cabrera et al 2000; McBride and Mills 1993; Lamb 1986). This is in stark contrast to the concept of maternal 
involvement, which is universalised and taken for granted (Miller 2011). Although some studies acknowledge maternal involvement - either as a predictor of paternal involvement (e.g. Pleck and Hofferth 2008) or as a measure from which to compare against paternal involvement (e.g. McBride and Mills 1993; LaFlamme et al. 2002), most do not focus on the definition and conceptualisation of maternal involvement given this is consistent and therefore less variable compared to paternal involvement (Miller 2010). The concept of paternal involvement is thus challenging to define and measure, with its definition and utility contested by scholars who emphasise its varied and subjective nature (e.g. Sanderson and Sanders-Thompson 2002; Coltrane and Parke 1998). For this reason, previous explorations of paternal involvement in childcare have been mainly pursued through more qualitative methods of research and/or are fairly small scale (e.g. Barry et al 2011; Doucet 2006; Dermott 2003; Miller 2010; 2011), although some research has started to focus on more widespread trends of fathering practices (e.g. McGill 2014; Norman et al, 2014; Calderwood et al 2005). What has been lacking is a more precise operationalisation of the 'involvement' concept. Morman and Floyd (2006: 116) assert that there is currently no 'quantitative tool' for measuring 'involved' fatherhood and claim that such an indicator would be useful in creating a benchmark for further research and conceptual elaboration as well as providing a method for operationalising the meaning of being an 'involved father'. McBride and Mills (1993) also point out that the lack of a clear and consistent definition of 'involved fathering' has hindered research on the paternal role.

This paper intends to partially address this shortfall by conceptualising and deriving two quantitative measures based on two dimensions of paternal involvement defined by Michael Lamb in 1986 (engagement and responsibility ${ }^{1}$ ). Simplifying a complex term into a quantitative measure allows us to capture and summarise a diverse set of practices that reaches out to all types of fathers. This is particularly useful for exploring paternal involvement across a large cohort

\footnotetext{
${ }^{1}$ Lamb's third dimension of accessibility is not explored due to data restrictions, which are discussed later.
} 
of fathers in order to help inform current UK policy debates on how to better support both fathers' and mothers' work-family reconciliation, which has been a key concern for both the previous Labour and Coalition Governments, as well as the current Conservative Goverment.

We use Confirmatory factor analysis on a sample of 11,767 households taken from the 2001-02 sweep of the UK's Millennium Cohort Study (MCS) ${ }^{2}$ to derive two quantitative measures of paternal involvement in childcare and housework when cohort children were aged nine months old, respectively defined as paternal engagement and responsibility. We use the MCS dataset because it is particularly rich with data on fathers' parenting roles, more so than the other national birth cohort studies conducted in Great Britain. ${ }^{3}$ We use Spearman's correlations to explore the association between paternal engagement in childcare and responsibility for housework and nine theoretically relevant variables from the MCS dataset. This reveals that fathers are more likely to be engaged and responsible when they work shorter hours, have a partner who works longer hours, have a high level of education and have more egalitarian gender role attitudes. Our analysis also reveals significant variations in paternal involvement according to the father's ethnicity. In our concluding and summary discussion of the paper, we reflect on these findings as well as the benefits and limitations of our involvement measures.

\section{Defining paternal involvement}

\footnotetext{
${ }^{2}$ Our analysis uses the Millennium Cohort Study (MCS), which is a nationally representative survey following a cohort of children born around the year 2000 in the UK. We use the first sweep of data, which was carried out in 2001/2 and covers a cohort of 18,819 babies aged nine months (brought up in 18,552 families) over a twelve month period starting in 2000 . The sample for this analysis has been filtered to include heterosexual couples only and all fathers who were not employed at sweep one were filtered out (10.5 per cent of households) in order to focus the study on men who all start with similar commitments to paid work (although this will vary by hours worked, type of job etc) and family. Fathers who did not take part in the survey were also filtered out (8.7 per cent of households) since no information about their parenting practices could be obtained. The final sample derived for this study therefore amounted to 11,767 , representing 63 per cent of the original MCS sample.

${ }^{3}$ The 1946 MRC National Survey of Health and Development, 1958 National Child Development Study, 1970 British Cohort Study
} 
The concept of paternal involvement or 'involved fatherhood' is challenging to define and measure, and its definition and utility is contested with some scholars emphasising its varied and subjective nature (e.g. Sanderson and Sanders-Thompson 2002; Coltrane and Parke 1998). Williams (2008) argues that it is a vague term, which does little to capture the complexity of fathering. Dermott (2003) argues that it is ambiguous because involvement can be interpreted in many ways; therefore most fathers could be described as 'involved' despite substantial variation in their situations and actions.

However, these critiques only apply when paternal involvement is used without clear operationalisation. A broad definition is provided by Dermott (2005: 92) who states that an 'involved' father is one who participates in the nurturing tasks involved in the 'taking care of' children. One way of thinking about this operationally is through the relative proportion of the childcare tasks done by each parent. Lewis and O'Brien (1987) point out that fathers who contribute to household labour in the form of doing housework might also be considered 'involved'. Material provision for the family, or 'breadwinning', is also regarded by some as an important dimension of a father's role (e.g. McGill 2014). However, for this paper, we argue that this is a role dimension or activity that is distinct from the core notion of 'involved fathering', which centres on ideas of nurturing and providing care. Of course, being a father also involves other activities connected with their socialisation and education; however, the nurturing side of fathering, as one element of paternal involvement, constitutes the main focus here.

In order to operationalise the concept of involvement, we refer to Lamb's (1986) work. He argued that there are three components of paternal involvement: accessibility, engagement and responsibility. The first dimension of accessibility signifies being physically available and present as a parent. This includes supervisory care or activities that require a less intensive degree of interaction, such as cooking in the kitchen while the child plays nearby, although a father can also 
be accessible whilst engaged in a non-child related activity. ${ }^{4}$ Thus, it is taken to refer to a secondary activity without one-to-one engagement in which the father is present and available for childcare if required either by the child or a partner.

Engagement, or interaction, Lamb argues, represents the one-to-one interaction time with the child, described by Lamb as the most intensive component of involvement because it is entirely child-centred. Examples include: feeding the child, helping the child with their homework and playing interactively. Lamb maintains that this does not include 'multi-tasking' activities e.g. doing the cooking whilst helping the child with homework as this involves a less intensive degree of interaction. $^{5}$

According to Lamb, responsibility is the third and most important component of involvement but is difficult to quantify because the planning, worry and thought that goes into being responsible often occurs when the parent is doing something else. Responsibility for the child's welfare and care is different from that of being able and willing to help out when convenient or when needed and mobilised by the 'main carer'. Responsibility involves knowing in detail what is needed and ensuring the particular aspects of childcare that are required are provided by anticipating, planning and arranging provision. For example, knowing when the child needs to go to the doctor, making the appointment and ensuring the child gets to it; making arrangements for childcare and ensuring the child has clothes to wear and food to eat. As mentioned earlier, one way a father might be responsible is to take responsibility for housework in order to maintain a clean and safe standard of living for the child; while also relieving the other parent (i.e. the mother) of these

\footnotetext{
${ }^{4}$ We note in passing here that these concepts are related Piaget's (1950) ideas of parallel and co-operative play and as with those the 'appropriate mix' of intensity will vary as the child develops.

${ }^{5} \mathrm{We}$ argue that this is too strong a definition of engagement; it seems uncontroversial that engaging with a child can be achieved alongside other activities, particularly when the child is very young. As long as the 'engaging' activities constitute direct interactions with the child the possibility that they are done alongside other tasks cannot be ruled out. For example, feeding the baby may be done alongside having a conversation with the mother or feeding other children in the household.
} 
tasks so that she can concentrate on other activities such as looking after the child. ${ }^{6}$ Indeed, Dermott (2008) argues that after the birth of a child, housework becomes an 'acknowledged task' because chores suddenly attain a child-specific dimension to them. For example, doing the laundry will most likely include the child's laundry and cleaning the house may be considered more important when the wellbeing of the child who lives there is taken into account. Thus, housework in households containing children is one form of implicit childcare, which must therefore be captured by one of Lamb's dimensions. Clearly, housework is not a form of engagement given this is not direct interaction with the child. Housework could, however, be a proxy measure for accessibility, particularly given Lamb himself describes accessibility as like 'cooking a meal while the child plays nearby'. Correlation tests confirm that housework is only very weakly related to accessibility (see footnote 17 , results section), which confirms that doing housework is either synonymous to responsibility, or represents some fourth dimension outside of Lamb's three dimensional classification. To identify which is the case, we need to operationalise the meaning of 'responsibility'. We argue that responsibility can be expressed in one of two ways: direct and/or indirect. Direct responsibility involves the planning of the child's day to day life and is closely associated with Lamb's definition (discussed above). However, indirect responsibility involves the support activities that provide a positive nurturing environment for the child. We argue that housework is one form of indirect responsibility, given it improves the quality of the child's environment, and is a partial measure of paternal responsibility. We acknowledge this does not capture the dimension of responsibility but our operationalisation is obviously constrained by the data available.

We acknowledge that Lamb's (1986) theory of involvement was developed over twenty years ago. This raises the question of whether a distinction between 'accessibility', 'engagement' and 'responsibility' remains pertinent, particularly as the nature of involvement changes over time

\footnotetext{
${ }^{6}$ Of course, this can work in reverse where fathers primarily look after the children while the other parent does the housework.
} 
and as children develop. This is exemplified by the more recent and extensive definitions of involvement provided by scholars such as Palkovitz (1997), Dermott (2008) and Pleck (2010) for example. This may suggest that paternal involvement is more complex with ways of being involved no longer falling into a simple, three dimensional classification.

Although Palkovitz, Dermott and Pleck provide a more in-depth and precise interpretation of the ways in which fathers can be involved, Lamb et al's three dimensional classification still provides the most useful summary measure because it can be applied to all fathers and all ages of child. For example, Palkovitz extends Lamb's three components into fifteen to include activities such as communication, shared interests, errands and cognitive processes, but these activities do not apply to the care of a newborn child. Similarly Dermott's (2008) 'going out for a meal' under the component of 'family time' does not apply to the care of a pre-school child. Furthermore, the detailed activities offered by Palkovitz and Dermott will not be relevant to all groups of fathers, such as those from different minority ethnic groups who may have different expectations about fathers and their roles (e.g. see Warin et al 1999; Haurai and Hollingworth 2009).

Here the advantage of Lamb's definition is that his three dimensions are broad and thus capture a diverse set of practices that reach out to all types of fathers and so can be useful for summarising the diversity of ways in which different fathers can be involved, particularly in the context of secondary data. Indeed, Haurai and Hollingsworth (2009) revert back to Lamb et al.'s three dimensions to group together the different fathering activities identified in their study. Finally, Lamb et al.'s three dimensions continue to be the most utilised and cited definition in social and psychological research, spanning three decades ${ }^{7}$ (e.g. LaRossa 1988; Volling and Belsky, 1991; McBride and Mills 1993; Sanderson and Sanders-Thompson 2002; Nangle et al 2003; O'Brien 2005;

\footnotetext{
${ }^{7}$ Although I note Pleck and Dermott's revisions have only been developed in the last three and five years respectively, Lamb et al's definition continues to be frequently cited in more recent research as shown in the following citations.
} 
Morman and Floyd 2006; Doherty, Farrell-Erikson, LaRossa 2006; Cabrera, Shannon, TamisLeMonda 2007; Pleck and Hofferth 2008; Haurai and Hollingsworth 2009; Norman 2010; Wilson and Prior 2011), which suggests the three dimensions of paternal involvement continue to be relevant and the most useful tool for categorising all types of childcare activities.

To this end, we use CFA to confirm whether variables measuring the contributions that a more recent cohort of fathers make to childcare and household can still be classified into one of Lamb's dimensions of paternal involvement. The next section discusses the approach that is taken in our analysis of the MCS, and some of the issues with measuring paternal involvement.

\section{Measuring paternal involvement in the Millennium Cohort Study}

There are several ways in which to capture paternal involvement empirically. For example, analysing parents' perceptions and accounts of their roles, relying on only mothers' or only fathers' reports of paternal contributions, comparing the amount of time men and women put into childcare and so on. Although we are restricted by the data available, we recognise that both parent's interpretations of paternal childcare contributions are important for research on this topic. Therefore, this study uses the fathers' accounts of their childcare practices when children are very young and the mothers' reports on fathers' contributions to housework. This use of a combination of mothers' and fathers' reports for different variables is primarily driven by the structure of the MCS questionnaire design but doing this may also allow us to gain a balanced perspective of fathers' involvement.

Of course there are still limitations with this. Cowdery and Knudson-Martin (2005: 343) argue that a focus solely on individuals level reporting of parenting roles ignores the complex network of 'interpersonal interactions' that takes place between fathers, mothers and children. They argue 
that it is important to consider the way in which parenting roles are negotiated and shared between fathers and mothers in order to understand fathering; in other words it is necessary to study how mothers and fathers 'create each other' when exploring fatherhood or motherhood. However, we argue that an analysis of interaction processes, namely how parents perceive and negotiate their childcare tasks, is only accessible through qualitative work, which is beyond the scope of this paper.

Using only mother's reports of fathers' contributions to domestic work is primarily driven by the way in which the MCS data is structured, that is the survey only collected data on these variables from the mother. However, we consider this to be valid measure based on Laurie and Gershuny's (2000) research which reports a high correlation (0.77) between fathers' and mothers' reports of their relative shares of domestic work in the British Household Panel Survey. They conclude that one respondent's account provides a relatively reliable estimate of the division of domestic labour in couples (cited by Calderwood et al, 2005). While parental reports of actual time spent on both childcare and housework can vary with spouses often overestimating their own contributions (see Kamo 2000; Mikelson 2008), the indicators used for this analysis (presented in the following section) are likely to be less prone to overestimation given they are based on very broad, summary measures. More importantly, because we are using factor analysis techniques the differences between mothers and fathers is not important here, the only issue is variance amongst fathers in their accuracy of reporting. Again given the broad summary measures that are used, this is less likely to be a problem.

\section{Selecting variables}


The first step was to select MCS variables that relate to paternal involvement. The questionnaire for the sweep one survey is divided into eleven modules according to topic ${ }^{8}$ with modules 2 (fathers involvement with baby), 8 (self-completion questions) and 9 (employment and education $)^{9}$ identified as containing variables that are relevant to paternal involvement in childcare and housework ${ }^{10}$.

Twenty sweep one variables were initially selected from three modules, however, conceptual analysis led to thirteen of the variables being dropped. This resulted in a total of seven variables identified as both capturing reliably and appearing to measure some underlying aspect of paternal involvement (see appendix for frequency tables and correlation matrix of the variables). Table 1 lists the twenty variables initially selected and highlights the final seven that were retained. In the MCS, data is collected from the 'main' parent (usually the mother) and where resident, their 'partner' parent (usually the father) through face-to-face interviews. Table 1 indicates which variables were and were not available for each respondent and highlights (in bold) the final seven variables that were retained for the factor analysis.

\footnotetext{
${ }^{8}$ Modules were: 1) Non-resident parents; 2) Father's involvement with the baby; 3) Pregnancy, labour and delivery; 4) Baby's health and development; 5) Childcare; 6) Grandparents and friends; 7) Parent's health; 8) A self-completion section (questions include attitudes to marriage, parenting, work and psychological assessments); 9) Employment and education; 10) Housing and the local area; 11) Interests and time with the baby.

${ }^{9}$ We selected variables from the Employment and Education module given previous research consistently shows that employment is one of the most important factors in determining paternal involvement in domestic work and the couples' division of labour (e.g. Dex \& Ward 2007; Hatten et al. 2002; Sayer et al. 2004; Singleton and Maher, 2004). Time spent in employment will have a negative effect on the time that fathers have available to engaged and responsible for their children.

${ }^{10}$ Although module 4 contained questions on child health and development, there were no measures of who takes most responsibility for the child's health, which would have been a suitable indicator for paternal responsibility. Instead, questions focus on the physical attributes of children to indicate their health such as their height and weight for instance. Module 5 contained questions on childcare, but there were no direct measures of how often fathers performed certain childcare tasks as was the case in module 2 . In the 'childcare' module 5, questions mainly focused on formal childcare arrangements and were only asked to the mother (i.e. main respondent). Although module 11 'time with baby' may appear relevant, there were only two questions that measured fathers' attitudes towards whether they felt they had enough time with their baby as opposed to how they actually used this time.
} 
Table 1: Sweep one variables that potentially measure paternal involvement at age nine months

\begin{tabular}{llll}
\hline & VARIABLE & \multicolumn{2}{l}{ RESPONDENT } \\
& & Partner & Main \\
\hline 1 & Total hours of work per week (inc overtime) [TOHR] / [WKHR]* & $\checkmark$ & $\checkmark$ \\
2 & Usual hours of work per week (exc overtime) [WOHR] & $\checkmark$ & $\checkmark$ \\
3 & Frequency works evenings [EVENING] & $\checkmark$ & $\checkmark$ \\
4 & Frequency works weekends [WKEND] & $\checkmark$ & $\checkmark$ \\
5 & Frequency works away overnight [OVNIGHT] & $\checkmark$ & $\checkmark$ \\
6 & Frequency works at night [NIGHT] & $\checkmark$ & $\checkmark$ \\
7 & Frequency spends time with friends [FRIEND] & $\checkmark$ & $\checkmark$ \\
8 & Frequency go out as a couple [COUPLE] & $\checkmark$ & $\times$ \\
$\mathbf{9}$ & Frequency looks after baby on own [BABY] & $\checkmark$ & $\mathbf{x}$ \\
$\mathbf{1 0}$ & Frequency feeds baby [FEED] & $\checkmark$ & $\mathbf{x}$ \\
$\mathbf{1 1}$ & Frequency changes baby's nappies [NAPPY] & $\checkmark$ & $\mathbf{x}$ \\
$\mathbf{1 2}$ & Frequency gets up in night for baby [GETUP] & $\times$ & $\checkmark$ \\
13 & Mostly around and generally looks after child [RBABY] & $\times$ & $\checkmark$ \\
14 & Mostly responsible for changing nappies [RNAPPY] & $\times$ & $\checkmark$ \\
15 & Mostly responsible for feeding baby [RFEED] & $\times$ & $\checkmark$ \\
16 & Mostly responsible for getting up at night for baby [RGETUP] & $\times$ \\
17 & Mostly responsible for looking after the baby when ill [BABYILL] & $\times$ & $\checkmark$ \\
$\mathbf{1 8}$ & Who takes most responsibility for cooking main meal [COOKING] & $\mathbf{x}$ & $\checkmark$ \\
$\mathbf{1 9}$ & Who takes most responsibility for laundry and ironing [LAUNDRY] & $\mathbf{x}$ & $\checkmark$ \\
$\mathbf{2 0}$ & Who takes most responsibility for cleaning the home [CLEANING] & $\mathbf{x}$ & $\checkmark$ \\
\hline *[TOHR] = Partner variable, [WKHR] = Main variable & & \\
\hline
\end{tabular}

* $[\mathrm{TOHR}]=$ Partner variable, $[\mathrm{WKHR}]=$ Main variable

Work hour variables ([TOHR] / [WKHR]) are a relevant measure of accessibility given this indicates the total amount of time the father is at work and away from his child. All other variables under this construct i.e. those that measured atypical patterns of paid work - [EVENING], [WKEND], [OVNIGHT] [NIGHT] [FRIEND] [COUPLE] - were discarded because although they appear to have face validity they are ambiguous with respect to overall involvement. For example, regular evening work would appear to suggest low involvement but evening work might be done on top of shorter working hours, which could lead to greater paternal involvement during the day (see Norman 2010 for a fuller discussion of the reasons for excluding these variables)

All of the other sweep one partner variables were retained as they measure core childcare and domestic work tasks. All fathers from the 'main' childcare variables are imputed into the partner 
variables ${ }^{11}$ because activities can be matched up with one exception: 'frequency fathers look after children when they are ill' [BABYILL] is a unique measure because there is no equivalent partner variable so this was dropped. Furthermore, looking after a child when he/she is ill does not constitute a core activity because it does not require an ongoing daily commitment from either parent; involvement is completely dependent on how often the child gets ill ${ }^{12}$. The three variables measuring domestic work were retained and are solely reliant on the reports of the main respondent, most of whom are mothers.

At this stage eight variables remained and a principal component analysis, which was used to initially explore the data of these variables produced three factors. However, factor three effectively consisted of a single variable - fathers (paid) work hours. Although in principle this is an appropriate proxy measure of accessibility, it cannot be used alone since further analyses on a single-item component in factor analysis would be equivalent to analysing the conditions that influence fathers' work hours, which is not the focus here hence the variable was dropped from the analysis. However, we note here that the results at this stage were consistent with the notion of accessibility being independent of the other two factors.

\footnotetext{
${ }^{11}$ The main respondent variables (numbers $13-16$ in Table) 1 were coded as follows: 1) Father does most ii) partner does most iii) someone else does most iv) shared equally. The partner respondent variables (numbers 9-12 in Table 1) were coded as follows: i) more than once a day ii) once a day iii) few times a week iv) once or twice a week v) less than once a week vi) never. Fathers from the main respondent variables who i) did the most or iv) shared the childcare task with a partner were filtered into the highest category of the partner respondent variable i) 'more than once a day'. Main respondent fathers who reported their ii) partner or iii) someone else doing the most childcare were filtered into the category of looking after the baby iii) 'a few times a week' in the partner respondent variable because this represents the average, middle frequency (not dissimilar from the other middle category of 'once or twice a week'). Since this is the next frequency down from the highest frequencies of 'more than once a day' and 'once a day', it can be assumed that fathers who are present (and responded to the main respondent questionnaire in the MCS) will contribute at least a moderate/average amount to their child's care, which is represented by this category. We note these variables do not measure exactly the same thing but there were only five fathers who were 'main' respondents so these imputations are unlikely to have a significant impact on the results. ${ }^{12}$ This situation also applies to [GETUP]: involvement is dependent on how often the baby wakes up at night. There was a small proportion of fathers with babies who never woke up at night $(13.1 \%, n=1,545)$. This variable was retained however; the implications of this decision are discussed in detail in Norman (2010).
} 
In summary, the final seven variables broadly measure the frequency fathers spend engaging in implicit or explicit childcare. So the measure of involvement derived here is based on how often fathers make contributions to these tasks. This is a key indicator of paternal involvement, further supported by Sayer et al. (2004) who argue that there is a cultural expectation for fathers to spend time with children; thus involved fathering generally means a greater time commitment to childcare. Measuring the frequency a father performs certain childcare and household tasks will indicate whether he has a high or low level of involvement.

\section{Using Factor Analysis to derive a measure of paternal involvement}

Factor analysis is one of the main methods of data reduction and works by exposing patterns of relationships between variables, identifying intercorrelated variables and reducing a large number of variables to a smaller number of factors that can be used in subsequent analyses. Thus, latent variables, which are not otherwise directly measurable, are identified through these techniques with parsimony achieved because the greatest amount of common variance is accounted for in a correlation matrix with the smallest number of explanatory components.

Following initial exploratory analyses using Principal Components Analysis and Principal Axis Factoring $^{13}$, Confirmatory factor analysis (CFA) was used to produce two latent measures. This method can be used to test a hypothesis about a predicted factor structure (i.e. that involvement can be defined in terms of engagement and responsibility). Specifically, CFA tests whether a proposed factor structure fits the data better than alternative structures so is used to confirm whether a two dimensional solution is better than a one-dimensional one (i.e. a solution where all variables load onto the same dimension).

\footnotetext{
${ }^{13}$ Principal Components Analysis (PCA) and Principal Axis Factoring (PAF) were used initially to explore the structure of the seven variables selected to measure involvement. This also helps to prepare the data for the final Confirmatory Factor Analysis (CFA), which tends to be used in the later stages of metric development to refine and improve solutions. Using all three data classification techniques serves to refine the latent measure of involvement so that it is accurate, reliable and fits the data in the most appropriate way (see Norman 2010 for the results of these tests).
} 
CFA confirms the structure of our measures by producing 'goodness of fit' indices, which are based on the variance remaining after the factors are taken into account. Our CFA model is derived by using the means and variances adjusted weighted least squares (WLSMV) option because the variables are categorical and so do not have multivariate normal distributions. This technique 'rescales' categorical, non-normal data through a scaling factor that adjusts for nonnormality resulting in a chi-square fit statistic ${ }^{14}$ adjusted for both mean and variance anomalies within the data, as well as more robust standard error terms. However, large sample sizes and non-normal data tend to bias the chi-square test in favour of model rejection so we use three alternative goodness-of-fit tests. The Bentler Comparative Fit Index (CFI) test compares the existing model fit with a null or independence model where the latent variables are assumed to be uncorrelated. The Tucker-Lewis Index (TLI) reflects the proportion by which the specified model improves fit compared to the null model. The third test - the Root Mean Square Error of Approximation (RMSEA) - relates to the residual in the model. This evaluates whether there is a close fit between model and data. Thus, the chi-square will be noted but successful model fit will be determined by the CFI, TLI and RMSEA.

\section{Results}

The CFA model specified a priori measurement model with two factors: the first factor had four item loadings - [BABY], [GETUP], [NAPPY], [FEED] - and the second factor had three item loadings: [COOKING], [CLEANING] and [LAUNDRY]. This followed the results from our initial exploratory analysis of the data using PCA and PAF, which suggested the seven variables could be combined into two linear components or factors that represented two dimensions of involvement (see Norman 2010 for results of the PCA and PAF) ${ }^{15}$.

\footnotetext{
${ }^{14}$ The main goodness-of-fit index in CFA that provides the difference between expected and observed covariance matrices.

${ }^{15}$ Given housework is a form of indirect childcare (e.g. see Dermott 2008), we test whether it should come under the remit of paternal responsibility or accessibility by running a Pearson's correlation between
} 
Tables 2 and 3 present the results of the CFA model ${ }^{16}$. Table 2 shows a summary of the model fit indices (CFI, TLI and RMSEA) for the independent model (when all variables are included). Table 3 shows the standardised parameter estimates of the variables (equivalent to the factor loadings in the PCA and PAF).

Table 2: Results of goodness-of-fit tests from the CFA

\begin{tabular}{llllll}
\hline & Chi-Square & df & CFI & TLI & RMSEA \\
\hline Baseline model & $23569.4^{* *}$ & 13 & -- & -- & -- \\
Independent model & $252.5^{* *}$ & 10 & 0.990 & 0.987 & 0.045 \\
\hline$* * \mathrm{p}=<0.001$ & & & & \multicolumn{2}{c}{ Source: MCS 1 ( $=10,112)$}
\end{tabular}

Table 3: Standardised parameter estimates from the CFA

\begin{tabular}{llll}
\hline Variable & Estimate & Std. Error & Est. Std. Error ${ }^{1}$ \\
\hline Factor 1 & & & \\
\hline BABY & $0.509^{* *}$ & 0.008 & 66.961 \\
FEED & $0.850^{* *}$ & 0.006 & 137.881 \\
GETUP & $0.403^{* *}$ & 0.010 & 41.325 \\
NAPPY & $0.817^{* *}$ & 0.006 & 126.167 \\
\hline Factor 2 & & & \\
\hline COOKING & $0.511^{* *}$ & 0.015 & 35.140 \\
CLEANING & $0.735^{* *}$ & 0.015 & 49.372 \\
LAUNDRY & $0.766^{* *}$ & 0.016 & 48.593 \\
\hline COIrelaton & & &
\end{tabular}

Correlation of factors $\mathbf{0} \mathbf{0 . 3 9 0}$

$* * p=<0.001$ Source: MCS $1(n=10,112)$

${ }^{1}$ Estimated Standard Error i.e. the estimate of the sample mean's standard error, i.e. $s / n$, where $n$ is the sample size and $\mathrm{s}$ is the estimate of the population standard deviation.

fathers' employment hours (i.e. his accessibility) and the factor of responsibility (i.e. housework). Results showed a very weak correlation (-.129), which confirms housework is not synonymous to accessibility. To test that housework is not a form of engagement, we ran a Pearson's correlation between the factor of responsibility and the factor of engagement. This also revealed only a weak relationship (-.124), which confirms it is also not synonymous to engagement. This confirms that housework, as a form of indirect childcare, is most synonymous to responsibility.

${ }^{16}$ Note the sample size has dropped by $14 \%$ to 10,112 cases. This is mainly due to 1,545 fathers being filtered out as missing in the 'frequency father gets up at night' variable because their baby never wakes up at night (see Table 1 in the Appendix). The remaining 110 cases are due to non-response 
In Table 2, the CFI, TLI and RMSEA show that the two-factor model is a good fit to the data. The CFI ranges from 0 to 1 where a value closest to 1 indicates a very good fit of the data; here the CFI is over the standard 0.9 cut-off, which indicates $99 \%$ of the covariation in the data can be reproduced by the given model. The TLI also confirms the model is a good fit of the data as a value closest to 1 indicates good model fit, with acceptable model fit indicated by a value of $>=.95$. Finally, the RMSEA takes a value between 0 and 1 with a smaller value indicating better model fit. Acceptable model fit is indicated by a value of 0.06 or less according to Chau and Hocevar (1995). The RMSEA for our model is less than the recommended cut-off of 0.06 providing further confirmation of good model fit.

In Table 3, the parameter estimates of the variables are listed along with their standard errors. Each estimate is statistically significant at the $1 \%$ level. All variables have very good loadings with the exception of three variables - [BABY] [COOKING] and [GETUP] - whose parameter estimates are considered to be fair but acceptable (according to guidelines recommended by Comrey and Lee, 1992). These loadings do contribute to well-defined factors so we do not choose to remove these variables at this point, but note that there appears substantial unique variability not captured by the factors.

The final analysis concerns the difference test or chi-square difference testing of measurement invariance, which establishes whether the specified two factor model fits the data better than a one factor model. The difference test value is statistically significant at the $1 \%$ level indicating that the two factor model fits the data significantly better than a one factor model. Thus, the CFA has produced two clearly defined factors of engagement and responsibility from seven variables taken from the MCS, which can be used in further analyses exploring paternal involvement with children under a year old. The two factors are only moderately correlated at 0.39 . 


\section{The predictors of involvement}

Following the derivation of our measures, we explored the relationship between the two factors of involvement and other theoretically relevant variables from the MCS dataset.

Two variables measuring fathers' and mothers' employment hours were selected given previous research highlights an association with paternal involvement in childcare (e.g. Norman et al 2014; Dermott 2008; Pailhe and Solaz 2008; Sayer et al. 2004; Warren 2003; Brayfield 1995). We expect fathers' employment hours to have a negative association with paternal engagement and responsibility given time spent in employment reduces the time that a father has available to be involved with his child. In contrast, we predict mothers' employment hours to have a positive association with paternal engagement and responsibility with the expectation that fathers will substitute for the reduction in the mothers' time with children.

Fathers' education was selected given previous, and notably older, research has shown a higher level of education leads to greater paternal involvement in childcare and household labour (Dale and Egerton 1997; Coltrane and Parke 1998; Arrighi and Maume 2000; Sayeret al. 2004b). Based on findings from these studies, we expect a positive association between level of education and paternal involvement.

We selected three variables measuring fathers' gender role attitudes. Data from the British Social Attitudes survey 2002, 2008 and 2012 shows a steady decline in support for a traditional division of labour in which the man takes primary responsibility for earning the income and the woman takes most responsibility for the home (e.g. Park et al. 2013; Crompton and Lyonette 2008). However, it is not entirely clear - given women continue to do more childcare and housework than men in the majority of UK households - that practice has followed stated attitudes. In spite of the ambiguous link between attitudes and practice, we expect to find a positive correlation 
between paternal involvement and more egalitarian gender role attitudes. That is, we expect fathers to be more engaged and show higher degrees of responsibility when they: (i) disagree that children suffer when their mother works before they start school; (ii) that family life suffers if women work full-time, and (iii) agree with the statement that fathers should be as closely involved in a child's upbringing as mothers.

We selected two variables measuring the frequency a father sees his own father and mother. We expect both variables to have a positive association with paternal involvement because frequent contact with a parent may suggest a close relationship, which may be replicated by a father in the form of engagement with his own child. For example, Dermott's (2003) study found that some fathers attempted to replicate positive aspects of their upbringing from their own fathers, such as high involvement in childcare (also see Dermott 2008; Merla 2005; Haurai and Hollingsworth 2009). However, little is known about the link between paternal involvement and the relationship fathers have with their own mother so this was also included as a variable here.

Finally, fathers' ethnicity was selected given paternal involvement according to different ethnic groups is an area that is fairly under-researched. Several, albeit older, studies suggest racial and ethnic differences in paternal involvement do exist. For example, Hofferth (2003) uses data from the 1997 US Panel Study of Income Dynamics to find black and Hispanic fathers exhibit greater responsibility for their children compared to white fathers. Cabrera et al.'s (2008) study, also based in the US, explores racial differences in non-resident paternal involvement to find nonresident white fathers have less involvement with their children compared to non-resident African American and Latino fathers. In the UK, Salway et al.'s (2009) research with Asian fathers finds most were involved in their child's care, contributing to feeding, bathing and other personal childcare tasks although mothers retained the main responsibility in these areas. Indeed, Toth and $\mathrm{Xu}(1999)$ argue that ethnic and racial differences in fathering are probable, and so underline 
the importance of explicating such differences in paternal involvement hence why we include ethnicity in this analysis This is variable is particularly important to include given the dearth of UK research on ethnic differences in father involvement.

Table four presents the Spearman's correlations for the relevant variables with our involvement measures.

Table 4 Spearman's correlations between selected ordinal variables and the involvement measures

\begin{tabular}{|l|c|c|}
\hline Variable & Engagement & Responsibility \\
\hline Employment hours & $-0.15^{*}$ & $-0.15^{*}$ \\
Total hours fathers normally work per week & $0.23^{*}$ & $0.26^{*}$ \\
Mother's working hours per week $^{\text {Education }}{ }^{a}$ & $0.01^{*}$ & $-0.04^{*}$ \\
\hline Father's education level & $-0.19^{*}$ & $-0.17^{*}$ \\
\hline $\begin{array}{l}\text { Attitudes (Likert) } \\
\text { Children suffer when their mother works before they start } \\
\text { school }\end{array}$ & $-0.16^{*}$ & $-0.16^{*}$ \\
$\begin{array}{l}\text { Family life suffers if women work full-time. } \\
\text { Children need their father to be as closely involved in their } \\
\text { upbringing as their mother. }\end{array}$ & $0.12^{*}$ & $0.04^{*}$ \\
\hline First Family Engagement & & \\
Frequency father sees own father & -0.01 & $-0.03^{*}$ \\
Frequency father sees own mother & 0.01 & -0.01 \\
\hline
\end{tabular}

*Statistically significant $(p<0.05)$

a'Compulsory or lower (GCSE or lower)'; 'Secondary level (A level/Diploma)'; 'Degree or Higher'

'Strongly agree'; 'Agree'; 'Neither agree nor disagree'; 'Disagree'; 'Strongly disagree'

'Once a year or less'; 'once a month'; 'once/twice a week'; '3-6 times a week'; 'every day'

Source: Millennium Cohort Study (2001-2) $(n=11,767)$ ?

Nearly all variables have statistically significant correlations in the expected direction with the two dimensions of paternal involvement. The exceptions are the frequency the father sees his own 
mother, which has no significant correlation with either dimension, and the frequency the father sees his own father, which has no significant correlation with engagement. However, all correlations are weak, which suggests each variable has little predictive power on the two factors of involvement. Interestingly, the strongest predictor is the mothers' employment hours, which is more predictive than the fathers own employment hours. This indicates that mothers' employment schedules are more influential than fathers' for fostering paternal involvement when the child is aged nine months old.

Another variable which has some predictive power is ethnicity. Figure one shows the group means for a course ethnic coding. Ignoring the two heterogeneous groups (mixed and other), all differences between groups are significant on both dimensions.

Figure 1: Group means for ethnic groups for engagement and responsibility measures.

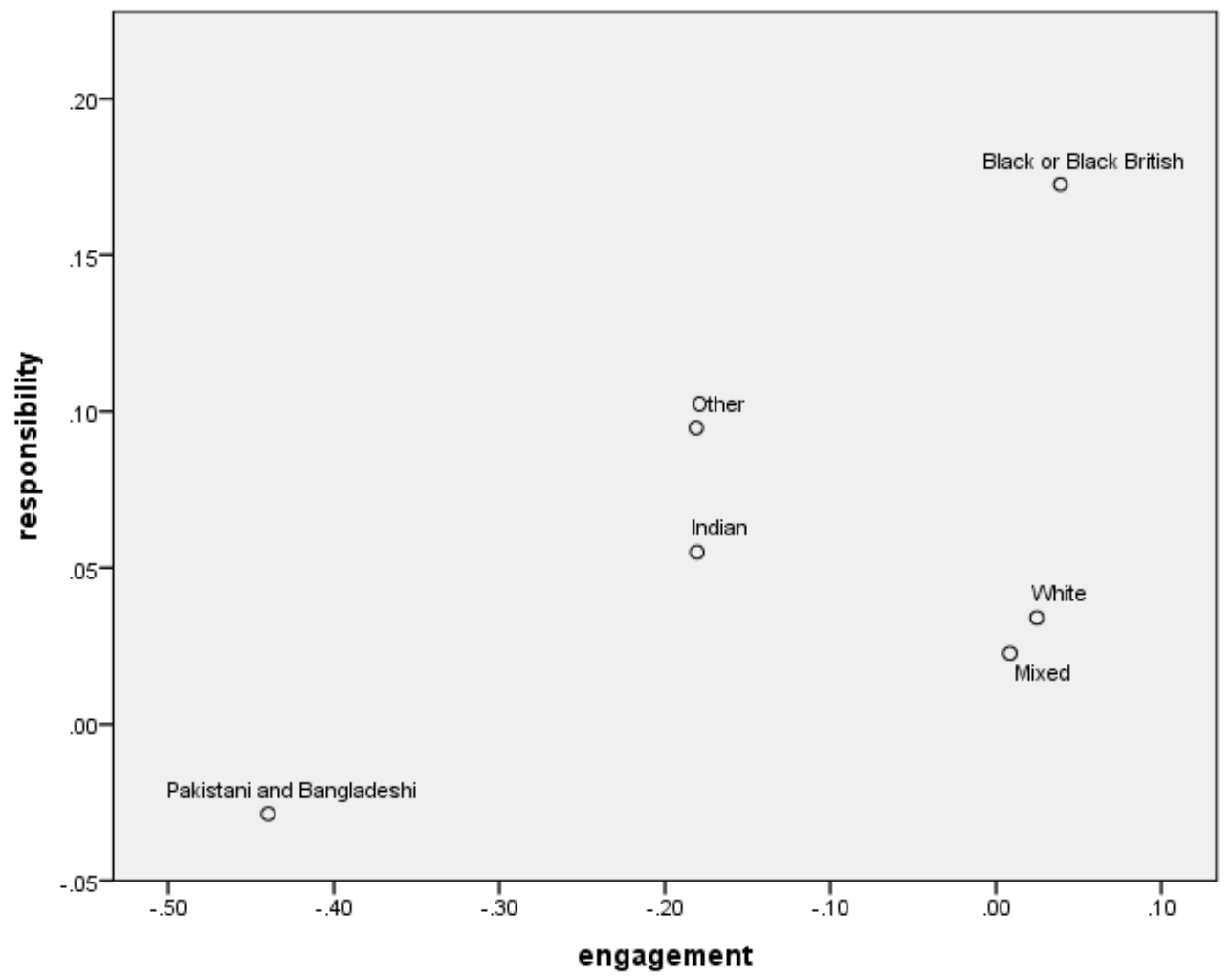


Black/Black British fathers are most likely to show most evidence of responsibility (through housework), and are also most likely to be engaged. White fathers have similar mean level of engagement to Black/Black British fathers but a lower mean level of responsibility for housework. Mean engagement and responsibility is lowest for fathers with a Pakistani and Bangladeshi background. Mean responsibility is higher for Indian fathers, but they are less likely to be engaged compared to White and Black/Black British fathers.

\section{Summary and conclusions}

This paper has described the process of deriving latent variables of paternal involvement for a sample of employed fathers within the MCS in order to represent their involvement with their children aged nine months old. Two dimensions of involvement - partially corresponding to two elements of Lamb's conceptualisation (engagement and responsibility) - were extracted from childcare and domestic work variables by confirmatory factor analysis. We refer to Lamb's theory to derive two measures of involvement because it provides the most comprehensive summary definition that can be applied to all fathers and all ages of child. This is particularly useful for the examination of paternal involvement for a large sample of fathers. Other definitions of involvement, such as those offered by Palkovitz (1997), Dermott (2008) and Pleck (2010) would be difficult to capture with secondary data given they extend the definition into more detailed parenting activities, which are not always measurable with survey data and not always applicable to the care of a baby.

The results from our CFA validate the theory that paternal involvement continues to be definable in terms of two broad dimensions - engagement and (indirect) responsibility. A measure of accessibility was not derived due to a lack of appropriate variables. Although this disrupts Lamb's three dimensional classification of paternal involvement, accessibility is considered the least 
important out of the three dimensions for this particular age of cohort child. At nine months old, the child will be unaware as to whether the father is 'there' for her or not; moreover, accessibility is perhaps more pertinent when children are older and do not require the same level of engagement from their parents, which at nine months, is more important in terms of the child's development (see Dermott 2008). We acknowledge that the variables used for the construct would require modification to measure involvement with older children given the constructs used here are based on tasks related to caring for a baby. Likewise, the indicators would require modification from the focus on the division of labour in couple households to build a construct for lone fathers or those who do not co-reside with their children.

We then explored the relationship between the involvement measures and other theoretically relevant variables in the MCS dataset through Spearman's correlations. Results show that paternal engagement and responsibility have a significant but weak association with both fathers' and mothers' employment hours, fathers' education, fathers' gender role attitudes and fathers' ethnicity. Paternal responsibility also has a very weak but significant association with the frequency a father sees his own father.

Interestingly, mothers' employment hours have a higher correlation with paternal engagement and responsibility than fathers' own employment hours. This highlights the importance of mothers' employment in shaping paternal involvement in childcare, and contradicts findings from earlier studies, which find no statistically significant relationship between mothers' employment and fathers' childcare time (e.g. Bryant and Zick 1996; Marsiglio 1991; Zick et al. 2001). This also supports findings from an earlier MCS analysis by Norman et al (2014), which finds mothers' employment hours to have the strongest association with paternal involvement when children are aged three. 
This may suggest a modest shift in gender relations is underway where it is no longer the fathers' but the mothers' employment that primarily shapes how involved a father is with his children. In two-parent households, fathers' labour market roles have historically been given precedence as the 'primary' earner in the couple (also see Warin et al. 1999) so this role is expected to dictate the amount of time available to spend with children. However, our results suggest this is no longer the case with the mothers' employment just as, or even more, important than the fathers' in shaping how involved he is in childcare and housework. Indeed, other research that finds the instance of 'maternal breadwinning' has increased. Ben-Galim and Thompson (2013) report that almost one in three (30 per cent) of all working mothers with dependent children are now the primary breadwinner for their family in the UK, either in the sense that they earn the same as or more than their partners, or as single mothers they provide the sole income for their family. As women are increasingly entering the labour market and taking on a breadwinner role, it may be that men have had to contribute more to childcare and housework in order to balance out these changes. Women's labour market participation could now be the main driver for fathers' involvement at home. However, despite the increase in the contributions that men make to childcare and domestic work over the last three decades as increasing number of women enter or return to the labour market after having children, women still do the most childcare and housework (see Crompton \& Lyonette, 2008; Dex, Hawkes, Joshi, \& Ward, 2005; Gray, 2006; Gershuny, 2000; Gershuny, Godwin, \& Jones, 1994; Lammi-Taskula, 2006; Singleton \& Maher, 2004). Furthermore, the type of care that parents provide continues to gendered. For example, Craig's (2006) study of Australian Time Use survey data found that mothering tended to involve more routine and physical care, and more overall responsibility for managing care (also see Spain and Bianchi 1996; Collinson and Hearn 2006). This suggests that fathers continue to have lower levels of (both direct and indirect) responsibility compared to mothers despite the increase in the absolute time that spend on caregiving. 
Another variable that has some predictive power is ethnicity with all differences between ethnic groups significant on both dimensions of engagement and responsibility. The variations in paternal involvement according to ethnicity may be related to cultural differences. Haurai and Hollingsworth (2009) argue that Pakistani and Black African parents tend to have more traditional views on gender compared to their White British or Black Caribbean counterparts with tradition and culture shaping fathers' behaviours and roles within Pakistani families. This partially supports our findings which show that Pakistani and Bangladeshi fathers are the least likely to be engaged and responsible than fathers from the other ethnic groups. Indeed, some Asian communities have fairly orthodox values about gender roles (e.g. see The Guardian $18^{\text {th }}$ December 2000), which may mean some Asian fathers are less likely to get involved in a traditionally maternal role. However, this is not to say that all Asian fathers as a group are uniformly less involved than white fathers, particularly as some studies have shown that many Asian fathers do make a significant contribution to their child's care (e.g. Salway and Chowbey 2009). The results here simply point to the need for further exploratory analyses on variations of paternal involvement by different ethnic classifications for there appears to be some small but significant differences; this is particularly relevant as some authors have noted research on this has been fairly limited to date (e.g. Salwey and Chowbey 2009). It is not possible to explore the reasons for the differences in paternal involvement according to ethnicity in greater detail here due to the nature of this analysis and the coding of the ethnic categories.

It is important to note that all associations between the key variables and the factors of paternal involvement are weak. This suggests there are other variables that have not been explored here, which shape paternal involvement when children are aged nine months. For example, it would be interesting to explore the association between paternal involvement and other, related variables such as fathers' values and beliefs, their confidence and motivation to be an involved parent, the 
culture of their workplace (e.g. in terms of father-friendliness), how much flexibility they have in their work schedules, peer group influences from their neighbourhood, community, friends, work colleagues, the relationship fathers have with their partners and the extent to which higher levels of engagement and responsibility are a choice or a necessity for fathers.

Our measure of paternal engagement is only applicable to the care of a baby, less than a year old. At this age, all babies require the same consistent care and supervision (e.g. all need their nappy changing regularly) so the measure developed in this paper is universal for this age (with the exception of very ill or disabled babies who will require a different level of care). This is useful for informing current policy debates given this is the age at which the most support tends to be provided to fathers (i.e. within the year following childbirth) so provides a useful benchmark for measuring paternal engagement with a baby. However, when children grow older, capturing paternal involvement through the frequency a father contributes to the childcare tasks that make up engagement becomes more difficult because these tasks become more diverse. Therefore, it would be necessary to derive a different engagement measure for older children - as we have done in a separate study exploring paternal involvement with toddlers for example (see Norman et al. 2014).

It is also important to note that developments in family policy to support fathers, which have occurred over the last decade or so, such as the introduction of paternity leave in 2003 , the extension of the right to request flexible working to all employees in 2014 and Shared Parental Leave, which was implemented in April 2015. While these initiatives may have some association with our measures of paternal involvement - possibly by encouraging fathers to be more engaged and responsible, this is unlikely to affect the measure itself. It would be interesting to explore the association between paternal involvement and paternity and parental leave, as well as different forms of flexible working, for a more recent cohort of fathers in order to assess the impact and success of these different levels of Government support. 


\section{Note}

This paper is based on work that was completed for Norman's ESRC funded (with quantitative stipend) PhD in Social Statistics. 


\section{Appendix}

Table 1: Frequency fathers contribute to the childcare tasks: looking after the baby, feeding the baby, changing the baby's nappy and getting up at night for the baby

\begin{tabular}{|l|l|l|l|l|}
\hline Frequency & $\begin{array}{l}\text { Look after } \\
\text { baby on own }\end{array}$ & Feed baby & $\begin{array}{l}\text { Change } \\
\text { nappy }\end{array}$ & $\begin{array}{l}\text { Get up at } \\
\text { night }\end{array}$ \\
\hline More than once a day & 15.5 & 24.3 & 35.5 & 7.0 \\
\hline Once a day & 15.1 & 28.4 & 19.7 & 8.1 \\
\hline A few times a week & 28.6 & 27.6 & 22.0 & 15.7 \\
\hline Once or twice a week & 24.2 & 10.2 & 7.3 & 14.5 \\
\hline Less than once a week & 12.6 & 5.7 & 7.4 & 17.3 \\
\hline Never & 3.8 & 3.7 & 8.0 & 24.2 \\
\hline Total & $\mathbf{9 9 . 9}$ & $\mathbf{9 9 . 9}$ & $\mathbf{9 9 . 9}$ & $\mathbf{8 6 . 8}$ \\
\hline Baby never wakes up & $\mathrm{n} / \mathrm{a}$ & $\mathrm{n} / \mathrm{a}$ & $\mathrm{n} / \mathrm{a}$ & 13.1 \\
\hline Missing: Not applicable/refusal & 0.1 & 0.1 & 0.1 & 0.1 \\
\hline TOTAL & $\mathbf{1 0 0 . 0}$ & $\mathbf{1 0 0 . 0}$ & $\mathbf{1 0 0 . 0}$ & $\mathbf{1 0 0 . 0}$ \\
\hline
\end{tabular}

Source: MCS 1, aged nine months $(n=11,767)$

Table 2: Frequency fathers contribute to the housework tasks: cooking the main meal, cleaning the house and doing the laundry and ironing

\begin{tabular}{|l|l|l|l|}
\hline Frequency & Cooking & Cleaning & Laundry \\
\hline Father does most & 10.9 & 2.0 & 2.2 \\
\hline Shares equally with partner & 21.8 & 20.6 & 13.9 \\
\hline Mother/other does most & 66.5 & 76.6 & 83.2 \\
\hline Total & $\mathbf{9 9 . 2}$ & $\mathbf{9 9 . 2}$ & $\mathbf{9 9 . 2}$ \\
\hline Missing: Not applicable/refusal & 0.8 & 0.8 & 0.8 \\
\hline TOTAL & $\mathbf{1 0 0 . 0}$ & $\mathbf{1 0 0 . 0}$ & $\mathbf{1 0 0 . 0}$ \\
\hline
\end{tabular}

Source: MCS 1, aged nine months ( $n=11,767)$

Table 3: Spearman's correlation matrix of the seven variables measuring paternal involvement

\begin{tabular}{|l|l|l|l|l|l|l|l|}
\hline & Baby & Feed & Nappy & Get up & Cooking & Cleaning & Laundry \\
\hline Baby & 1.000 & & & & & & \\
\hline Feed & 0.403 & 1.000 & & & & & \\
\hline Nappy & 0.357 & 0.645 & 1.000 & & & & \\
\hline Get up & 0.192 & 0.296 & 0.285 & 1.000 & & & \\
\hline Cooking & 0.117 & 0.172 & 0.207 & 0.073 & 1.000 & & \\
\hline Cleaning & 0.104 & 0.136 & 0.151 & 0.065 & 0.232 & 1.000 & \\
\hline Laundry & 0.093 & 0.131 & 0.151 & 0.078 & 0.199 & 0.406 & 1.000 \\
\hline
\end{tabular}

Source: MCS 1, aged nine months $(n=11,767)$ 


\section{References}

Arrighi, B. and Maume, D. (2000) Workplace subordination and men's avoidance of housework. Journal of Family Issues Vol. 21 Issue 4, p. 464-487.

Barry, A., Smith, J., Deutsch, F., Perry-Jenkins, M. (2011) Fathers' Involvement in Child Care and Perceptions of Parenting Skill Over the Transition to Parenthood. Journal of Family Issues, Vol. 32, Issue 11, p. 1500-1521.

Ben-Galim, D. and Thompson, S. (2013): Who's Breadwinning? Working mothers and the new face of family support. London, Institute for Public Policy Research.

Brayfield, A. (1995). Juggling Jobs and Kids: The Impact of Employment Schedules on Fathers Caring for Children. Journal of Marriage and Family 57: 321-332.

Bryant, W. K. and Zick, C.D. (1996) An examination of parent-child shared time. Journal of Marriage and Family, Vol. 17, p. 365-392.

Cabrera, N. Tamis-LeMonda C. Bradley, R. Hofferth, S. and Lamb, M. (2000). Fatherhood in the Twenty-First Century. Child Development, Volume 71, Issue 1, p. 127-136.

Calderwood, L. and Kiernan, K. Joshi, H. Smith, K. Ward, K. (2005). Parenthood and Parenting in S. Dex and H. Joshi Children of the 21st Century: from birth to nine months. Bristol, The Policy Press.

Chau, H. and Hocevar, D. (1995) The effects of number of measured variables on goodness-of-fit in confirmatory factor analysis. Paper presented at the annual conference of the American Educational Research Association, San Francisco.

Collinson, D. L. and J. Hearn (1996). 'Men' at 'Work': Multiple Masculinities/Multiple Workplaces in "Understanding Masculinities: Social Relations and Cultural Arenas". M. Mac an Ghaill. Buckingham and Philadelphia, Open University Press.

Coltrane, S. and Parke, R. (1998). Reinventing Fatherhood: Toward an Historical Understanding of Continuity and Change in Men's Family Lives. Philadelphia, National Center on Fathers and Families.

Comrey, A. L., and Lee, H. B. (1992). A first course in factor analysis (2nd ed.). Hillside, NJ: Erlbaum.

Cowdery, R. S. and Knudson-Martin, C. (2005) The Construction of Motherhood: Tasks, Relational Connection and Gender Equality. Family Relations, Volume 54, Issue 3, p. 335-345

Craig, L. (2006): Does Father Care Mean Fathers Share? A Comparison of How Mothers and Fathers in Intact Families Spend Time with Children, Gender and Society, April 2006: vol. 20, no. 2, p. $259-281$

Crompton, R. and Lyonette, C. (2008) Who does the housework? The division of labour within the home in A. Park, J. Curtice, K. Thomson, M. Phillips, M. Johnson, and E. Clery (Eds.) British Social Attitudes: The $24^{\text {th }}$ Report. London, Sage.

Dale, A. and Egerton, M. (1997). Highly educated women: evidence from the national child development study. London, Stationary Editor. 
Dermott, E. (2003). The Intimate Father': Defining paternal involvement. Sociological Research Online, Volume 8, Issue 4

Dermott, E. (2008). Intimate Fatherhood: A sociological analysis. Oxon, Routledge.

Dex, S., Hawkes, D. Joshi, H. \& Ward, K.(2005). Parents' employment and childcare. Children of the 21st Century: From birth to nine months. S. Dex and H. Joshi. Bristol, Policy Press.

Dex, S. and Ward, K. (2007). Parental Care and Employment in Early Childhood: Analysis of the Millennium Cohort Study (MCS) Sweeps 1 and 2. London, Equal Opportunities Commission

Doherty, William J., Farrell Erickson, M. and LaRossa, R. (2006) “An Intervention to Increase Father Involvement and Skills with Infants during the Transition to Parenthood." Journal of Family Psychology 20:438-47

Doucet, A. (2006). 'Estrogen-filled worlds': fathers as primary caregivers and embodiment. The Sociological Review, Volume 54, Issue 4, p. 696-716.

Gershuny, J. (2000). Changing Times: work and leisure in postindustrial society. Oxford, Oxford University Press.

Gershuny, J., Godwin, M. and Jones, S. (1994). The Domestic Labour Revolution: A process of Lagged Adaptation in "The Social and Poltical Economy of the Household". M. Anderson, F. Bechhofer and J. Gershuny. Oxford, Oxford University Press

Gray, A. (2006). The Time Economy of Parenting. Sociological Research Online 11(3).

The Guardian (18 December 2000). Asians fly the flag for traditional family life, http://www.theguardian.com/uk/2000/dec/18/britishidentity.race (accessed 16 May 2014).

Hatten, W., L. Vinter, et al. (2002). Dads on Dads: Needs and expections ay home and at work. London, Equal Opportunities Commission.

Hauari, H. and Hollingworth, K. (2009). Understanding Fathering: Masculinity, diversity and change. London, Joseph Rowntree Foundation.

Hofferth, S. (2003). Measuring Father Involvement and Social Fathering: An Overview. Measurement Issues in Family Demography. Maryland, USA

Kamo, Y. (2000) 'He Said, She Said': Assessing Discrepancies in Husbands' and Wives' Reports on the Division of Household Labour. Social Science Research, Volume 29, p. 459-476.

La Rossa, R. (1988) 'Fatherhood and Social Change', Family Relations, Vol. 37, pp. 451-457

Laflamme, D., Pomerleau, A., Malcuit, G. (2002) “A Comparison of Fathers' and Mothers' Involvement in Childcare and Stimulation Behaviors During Free-Play with Their Infants at 9 and 15 Month"', Sex Roles, Vol 47(11-12), pp.507-518

Lamb, M. (ed) (1986). The Father's Role: Applied Perspectives. New York, John Wiley \& Sons. 
Lammi-Taskula, J. (2006). Nordic men on parental leave: can the welfare state change gender relations? in Politicizing Parenthood in Scandinavia: Gender relations in welfare states. A. Ellingsaeter and A. Leira. Bristol, Policy Press.

Lewis, C. and M. O'Brien (1987). Reassessing Fatherhood: new observations on fathers and the modern family. London, Sage

Marsiglio, W. (1991) Paternal Engagement Activities with Minor Children. Journal of Marriage and Family, Volume 53, Issue 4, p. 973-986.

Mcbride, B. and G. Mills (1993) A Comparison of Mother and Father Involvement With Their Preschool Age Children. Early Childhood Research Quarterly, Volume 8, p. 457-477.

McGill, B. (2014): Navigating New Norms of Involved Fatherhood: Employment, Fathering Attitudes, and Father Involvement, Journal of Family Issues, February 10, 2014

Merla, L. (2005). Identity Implications of Being a Housefather in Belgium. Paper prepared for the Society for the Advancement of Socio-Economics 17th Annual Meeting, Central European University and Budapest University of Economic Sciences, Budapest

Mikelson, K. (2008) He Said, She Said: Comparing Mother and Father Reports of Involvement. The Journal of Marriage and Family, Volume 70, p. 613-624.

Miller, T. (2010) Making Sense of Fatherhood: Gender, Caring and Work, Cambridge University Press: Cambridge

Miller, T. (2011) Falling back into Gender? Men's Narratives and Practices around First-time Fatherhood, Sociology, vol. 45 no. 6: 1094-1109

Morman, M. and K. Floyd (2006) Good Fathering: Father and Son Perceptions of What It Means to Be a Good Father, Fathering, Volume 4, Issue 2, p. 113-136.

Nangle, S., M. Kelley, et al. (2003). Work and Family Variables as Related to Paternal Engagement, Responsibility, and Accessibility in Dual-Earner Couples with Young Children. Fathering 1(1).

Norman, H. (2010): Involved fatherhood: An analysis of the conditions associated with paternal involvement in childcare and housework. (Unpublished doctoral thesis). University of Manchester.

Norman, H. Elliot, M., Fagan, C. (2014): Which fathers are the most involved in taking care of their toddlers in the UK? An investigation of the predictors of paternal involvement, Community, Work \& Family, 17:2, p. 163-180

O'Brien, M. (2005). Shared caring: bringing fathers into the frame. Working Paper Series No. 18, Manchester: Equal Opportunities Commission.

Pailhe, A. and A. Solaz (2008). Time with Children: Do Fathers and Mothers Replace Each Other When One Parent is Unemployed? European Journal Population 24: 211-236.

Palkovitz, R. (1997): Reconstructing involvement: Expanding conceptualizations of men's caring in contemporary families, in Hawkins, A.J., Dollahite, D.C. (eds): Generative fathering: Beyond deficit perspectives. Thousand Oaks CA, Sage 
Park, A., Bryson, C., Clery, E., Curtice, J. and Phillips, M. (2013): British Social Attitudes 30, 2013 Edition, London, Natcen.

Piaget, J. (1950): The Psychology of Intelligence. London: Routledge

Pleck, J. (2010): Paternal involvement: Revised conceptualization and theoretical linkages with child outcomes in M. E. Lamb (Ed.), The role of the father in child development, 5th ed, New York, Wiley.

Salway, S. and Chowbey, P. (2009). Understanding the experiences of Asian Fathers in Britain. London, Joseph Rowntree Foundation.

Sanderson, S. and V. Sanders-Thompson (2002) Factors Associated With Perceived Paternal Involvement in Childrearing. Sex Roles, Volume 46, Issue 3/4, p. 99-111.

Sayer, L., S. Bianchi, et al. (2004) Are Parents Investing Less Time in Children? Trends in Mothers' and Fathers' Time with Children. American Journal of Sociology, Volume 110, Issue 1, p. 1-43.

Sayer, L., Gauthier, A., Furstenberg, (2004b) Educational Differences in Parents' Time With Children: Cross-National Variations. Journal of Marriage and the Family, Volume 66, p. 1152-1169

Singleton, A. and J. Maher (2004). The 'New Man' Is in the House: Young Men, Social Change, and Housework. The Journal of Men's Studies 12(3): 227-240.

Spain, D. and S. Bianchi (1996). Balancing Act: Motherhood, Marriage and Employment among American Women. New York, Russell Sage Foundation.

Toth, J., F. and Xu, X. (1999) Ethnic and Cultural Diversity in Fathers' Involvement: A racial/ethnic comparison of African American, Hispanic and While fathers, Youth and Society, Volume 31, p. 7699

Warin, J., Y. Solomon, Lewis, \& Langford (1999). Fathers, Work and Family Life. Findings. London, Joseph Rowntree Foundation

Warren, T. (2003). Class and Gender-based Working Time? Time Poverty and the Division of Domestic Labour. Sociology 37(4): 733-752

Williams, S. (2008) What is Fatherhood: Searching for the reflexive father. Sociology, Volume 42, Issue 3, p.487-502.

Wilson, K., Prior, M. (2011): Father involvement and child well-being, Journal of Paediatrics and Child Health, Vol 47, Issue 7, p.p 405-407

Volling, B. L., \& Belsky, J. (1991). Multiple determinants of father involvement during infancy in dual-earner and single earner families. Journal of Marriage and the Family, 53, 461-474.

Zick, C. D., Bryant, W.K. and Osterbacka, E. (2001): Mothers' Employment, Parental Involvement and the Implications for Intermediate Child Outcomes, Social Science Research, Volume 30, p. 2549 
